\title{
Correction to: National environmental policies as shelter from the storm: specifying the relationship between extreme weather vulnerability and national environmental performance
}

\author{
Todd A. Eisenstadt ${ }^{1} \cdot$ Daniel J. Fiorino ${ }^{1} \cdot$ Daniela Stevens $^{1}$ (D)
}

Published online: 5 December 2018

(C) AESS 2018

Correction to: Journal of Environmental Studies and Sciences

https://doi.org/10.1007/s13412-018-0523-4

The original version of this article unfortunately contained a mistake. The name of "Todd A. Eisenstadt" is now corrected in the author group of this article. The original article has been corrected.

Publisher's Note Springer Nature remains neutral with regard to jurisdictional claims in published maps and institutional affiliations.

The online version of the original article can be found at https://doi.org/ 10.1007/s13412-018-0523-4

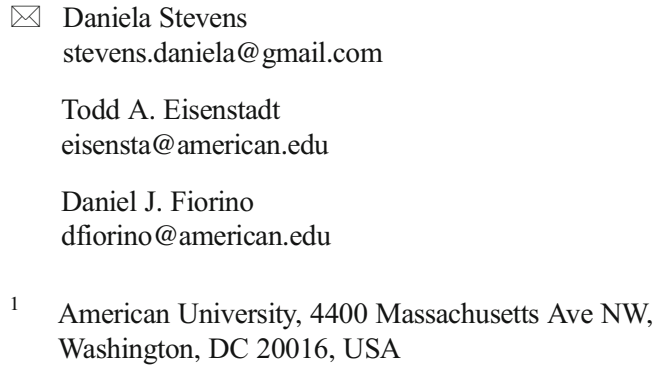

